\title{
Designing a Pharmacist Opioid Safety and Intervention Tool
}

\author{
Brendan Woods, Michael Legal, Stephen Shalansky, Tamara Mihic, and Winnie Ma
}

\begin{abstract}
Background: Despite the recent increase in opioid overdoses across Canada, few pharmacy-led initiatives have been implemented to address issues related to opioid prescribing in the hospital setting.

Objectives: The primary objective of this study was to develop a clinical tool, intended for use by hospital pharmacists and informed by best practices from the literature, that would provide a structured approach to enhancing the safety of opioid prescribing. The secondary objective was to collect pharmacists' opinions about the feasibility and utility of this tool.
\end{abstract}

Methods: A comprehensive literature search and pharmacist focus group analysis provided content for development of a candidate clinical tool. This tool was then piloted by clinical pharmacists working on general medical and surgical units in a single hospital. Pharmacists participating in the pilot were invited to complete an online survey concerning their perceptions of the tool. Descriptive statistics were used to analyze the survey results.

Results: The literature search and focus group analysis led to development of a candidate clinical tool that focused on Medication review, Optimization, Reassessment, and Education (MORE). It included key risk factors relating to opioid safety, along with suggested mitigating strategies. The MORE tool was piloted for 3 weeks by 14 clinical pharmacists, 9 of whom responded to the subsequent survey. Five respondents indicated that the clinical tool increased their ability to identify risk factors. Five respondents also noted an increase in their ability to identify possible interventions. Most respondents felt that the tool was useful and that it would be feasible to integrate it into their practice; however, they noted that a more streamlined version could improve ease of use.

Conclusions: The MORE tool was well received by clinical pharmacists. Implementation of the tool into routine practice requires additional changes to improve ease of use. Suggestions for modifying and streamlining the tool will be incorporated into future versions.

Keywords: opioids, pharmacist, stewardship, clinical tool

Can J Hosp Pharm. 2020;73(1):7-12

\section{RÉSUMÉ}

Contexte : Malgré l'augmentation récente des surdoses d'opioïdes au Canada, peu d'initiatives menées sous la houlette de pharmacies ont été mises en place sur les enjeux potentiels liés à la prescription d'opiacés en milieu hospitalier.

Objectifs : L’objectif principal de cette étude visait à élaborer un outil destiné aux pharmaciens d'hôpitaux, s'inspirant des meilleures pratiques rapportées dans la documentation, qui fournirait une approche structurée pour améliorer la sécurité de la prescription d'opioïdes. L'objectif secondaire consistait à recueillir les opinions des pharmaciens sur la faisabilité et l'utilité d'un tel outil.

Méthode : Des recherches bibliographiques étendues ainsi qu'une analyse de groupes de discussion de pharmaciens ont fourni le contenu nécessaire à l'élaboration d'un outil clinique expérimental. Ensuite, cet outil a été testé par des pharmaciens cliniciens travaillant dans des unités médicales générales et chirurgicales au sein d'un seul hôpital. Les pharmaciens participant au projet pilote ont été invités à répondre à une enquête en ligne sur leur perception de l'outil. Des statistiques descriptives ont permis d'analyser les résultats de l'enquête.

Résultats : Les recherches bibliographiques et l'analyse des groupes de discussion ont débouché sur le développement d'un outil clinique nommé MORE [pour Medication review, Optimization, Reassessment, and Education, ou Examen, optimisation, réévaluation et éducation aux médicaments]. Il comprenait des facteurs de risque liés à la sécurité des opioïdes ainsi que des suggestions de stratégies d'atténuation. Quatorze pharmaciens cliniciens, dont neuf ont répondu à l'enquête qui a suivi, ont testé le MORE pendant trois semaines. Cinq répondants ont indiqué que l'outil clinique augmentait leur capacité à déterminer les facteurs de risque. Cinq ont également noté une meilleure capacité à déterminer les interventions possibles. La plupart des répondants ont estimé que l'outil était utile et qu'il serait possible de l'intégrer dans leur pratique; cependant, ils ont aussi noté qu'une version simplifiée pourrait faciliter son utilisation.

Conclusions : Les pharmaciens cliniciens ont bien accueilli l'outil MORE. Sa mise en ouvre dans la pratique courante exige cependant des changements supplémentaires pour faciliter son utilisation. Les versions à venir tiendront compte des propositions visant à le modifier et à le simplifier.

Mots-clés : opiö̈des, pharmacien, intendance, outil clinique 


\section{INTRODUCTION}

$\mathrm{T}$ he opioid crisis has had an immense impact on the individuals affected, their families, and the health care system, including in the province of British Columbia. ${ }^{1}$ A recent report published by the government of Canada stated that there were 13900 opioid-related deaths in Canada between January 2016 and June 2019. ${ }^{2}$ An average of 4 deaths each day in British Columbia are due to opioid overdoses, and the proportion of emergency department visits attributed to opioid overdose is as high as $25 \%$ in some centres. ${ }^{3,4}$ Contamination of the illicit drug supply with fentanyl has been a major driver of overdose deaths.

Previous studies have suggested that individuals who misuse prescription opioids are more likely to turn to illicit street drugs that put them at risk for overdose. ${ }^{5}$ Canada is currently second only to the United States in the number of opioid prescriptions written per capita, and in the past 12 years the quantity of opioids prescribed has tripled across the country. ${ }^{6,7}$ Prescribing of opioids upon hospital discharge has been associated with a 5-fold higher rate of chronic opioid use and a greater risk of adverse effects and overdose among previously opioid-naive patients, compared with those who did not receive opioids upon discharge from hospital. ${ }^{8}$ This suggests that intervening on inappropriate opioid prescriptions may help to decrease chronic opioid use and progression to opioid use disorder. A document produced by the University of Massachusetts provides support for a prevention-focused model regarding opioid misuse.

A variety of community programs have been implemented to help address the opioid crisis, but few initiatives have targeted hospital practice. The Canadian Society of Hospital Pharmacists recently released a guideline addressing proper inventory management, dispensing, and distribution of opioid medications in hospitals and other health care settings. ${ }^{10}$ However, when we initiated the present study, no formal pharmacist-led clinical programs focusing on in-hospital opioid prescribing had been implemented in Canada.

In the United States, some efforts have been made to promote optimal opioid use in the hospital setting. A pharmacistled pain management stewardship program in Minnesota involved medication reconciliation, care plan guidance, and decentralized rounding for patients with prescriptions for long-acting oral opioids, high-dose opioids, methadone, and fentanyl. ${ }^{4}$ Over a 1-year period, $16 \%$ of all patients admitted to the hospital were reviewed, and pharmacists made interventions for $44 \%$ of these patients. ${ }^{4}$ A similar approach customized for the patient population in the authors' institution could be beneficial.

St Paul's Hospital is a 430-bed inner city tertiary care teaching hospital in Vancouver, British Columbia. The opioid crisis has had a major impact in the local community, and the hospital's clientele includes a significant proportion of patients with active opioid use disorder. Unpublished data from St Paul's Hospital indicated that $50 \%$ of patients receive a prescription for an opioid during their hospital admission. To date, no new resources have been provided to target opioid prescribing in the hospital or at discharge. Therefore, there is a need to empower existing staff to optimize opioid prescribing, especially for patients who have risk factors for opioid-related adverse events. This study aimed to develop a literature-informed clinical tool centred around best practices, to assist hospital pharmacists in identifying risk factors in their patients and to provide guidance on possible interventions to address these risk factors. Such an approach could provide a framework for other groups across the country to emulate. The secondary objective of the study was to pilot the tool and assess its usability and the feasibility of incorporating it into daily practice.

\section{METHODS}

\section{Scope}

The research team elected to target the proposed clinical tool toward pharmacists caring for patients on general inpatient medical and surgical wards. Patients in critical care areas and the emergency department and those being treated by the palliative care team have specific needs related to opioid analgesia; therefore, pharmacists working in these areas of the hospital were excluded from the pilot phase of the study. Participating pharmacists were also instructed to avoid applying the tool for patients being followed by the addiction medicine, acute pain, and chronic pain services, so as to focus efforts on patients who did not already have experts assessing their opioid therapy. Finally, because St Paul's Hospital does not have a dedicated oncology unit or service, patients with cancer-related pain are sometimes encountered but represent only a minority of admissions. No specific guidance was built into the tool to differentiate between patients with noncancer pain and those with cancer-related pain.

\section{Design}

Development of the final tool involved 4 separate phases (Figure 1). Phase 1 was intended to inform the tool content and context through literature searches and focus groups of clinical pharmacists. Phase 2 focused on formulation of the clinical tool itself. Phase 3 involved piloting the candidate clinical tool, and Phase 4 involved deployment of a survey to participating pharmacists to gauge their perceptions of it (especially pertaining to usability and feasibility). The study protocol was approved by the local Behavioural Research Ethics Board, and informed consent was obtained from all pharmacist participants before their involvement in the study.

\section{Phase 1: Informing Tool Content and Context}

A literature search was conducted to answer 3 key questions:

1. Which patient-specific factors or characteristics are associated with an increased risk of adverse outcomes in patients for 
whom opioids are prescribed (e.g., opioid overdoses, hospital admissions, substance use disorders)?

2. Which opioid prescribing practices/patterns are associated with an increased risk of adverse outcomes?

3. Which interventions (pharmacy-based or otherwise) have been shown to mitigate the risks described in questions 1 and 2 ?

Two members of the research team (B.W., M.L.) searched multiple databases, specifically Ovid MEDLINE, PubMeb, Embase, CINAHL, and Google Scholar, with date limits from 1960 to 2017. All article types were included. The search was comprehensive but was not intended to be a formal systematic review of the literature. The search terms were "opioid" or "opioid analgesics", "prescribing" or "inappropriate prescribing", "risk factors" or "risk assessment", "prescription drug misuse" or "misuse", "hospital”, "pharmacist", “interventions", "opioid stewardship", and "adverse drug events". The investigators manually screened the search results and further refined the search in an iterative manner. Relevant studies were summarized to produce a list of risk factors for opioid misuse/use disorder and other adverse events, inappropriate prescribing practices, and interventions utilized at other sites to promote opioid stewardship and safety.

In addition to the literature search, 3 focus groups involving clinical pharmacists were conducted at St Paul's Hospital. The pharmacist focus groups were intended to gauge pharmacists' baseline perspectives about the need for an opioid stewardship program or intervention, the role that pharmacists should have

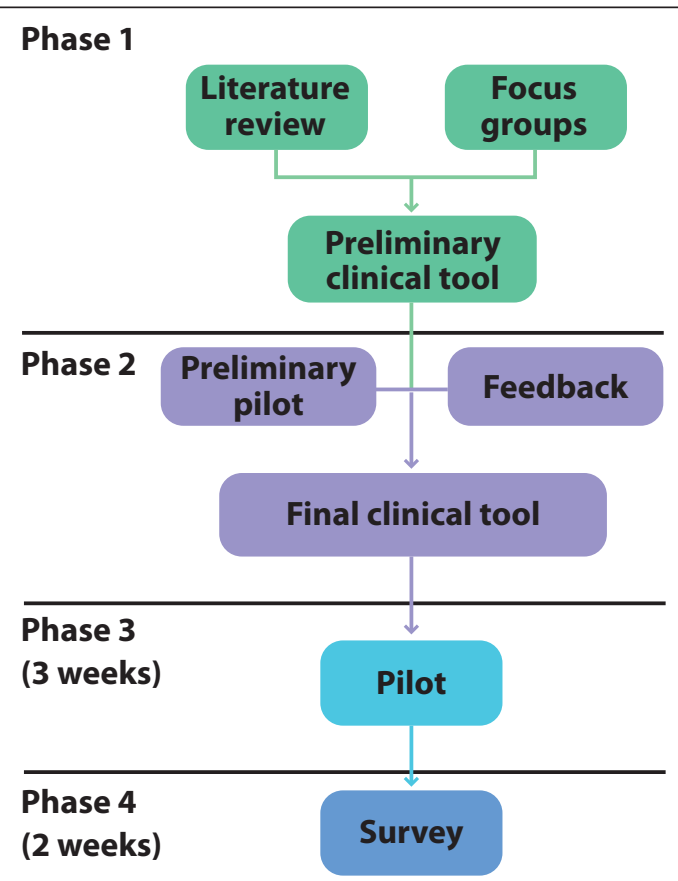

Figure 1. Phases of the study. in such a program, potential barriers to implementation, and key content to consider in tool development. Each focus group was scheduled for 30 minutes and involved at least 4 clinical pharmacists across a variety of specialties. Pharmacists were invited via an e-mail message distributed to all clinical pharmacists (using a "blind cc" distribution list) by pharmacy administration. A structured question list (Appendix 1, available at https:// www.cjhp-online.ca/index.php/cjhp/issue/view/195/showToc) was used, and at least 1 facilitator and 1 transcriber from the research team were present at each session. Each session was audiorecorded (with the verbal and written consent of all participants), and the transcriber who was present during the session reviewed the recording and transcribed it verbatim. The transcripts were then analyzed using the Theoretical Domains Framework, a validated tool for the qualitative analysis of focus groups. ${ }^{11,12}$ Each transcript was analyzed independently by at least 2 members of the research team, and each participant utterance was coded using the Theoretical Domains Framework. In the case of discrepancies in coding, the 2 team members first attempted to resolve them through discussion; if a consensus was not reached, a third member of the team made the final decision.

\section{Phase 2: Formulating a Preliminary Clinical Tool}

Using the content gathered in phase 1, the research team developed a preliminary clinical tool. Principles considered in designing the tool included provision of a simple stepwise approach in the form of a 1-page reference that pharmacists could bring with them to the patient care unit. It was also important that the tool be suitable for assisting pharmacists to quickly identify patient risk factors and suboptimal opioid prescribing and then offer strategies to optimize therapy and mitigate risk. Finally, the tool was intended to blend literature-derived risk factors and interventions with practical approaches and considerations supplied by the clinical pharmacist focus groups. A draft of the preliminary tool was provided to a physician specializing in addictions for review and feedback. The preliminary tool was also field-tested by 4 clinical pharmacists who used the tool for 1 day each in their practice. Once final edits were made to the tool, the final "candidate tool" was ready for the larger pilot in phase 3.

\section{Phase 3: Piloting the Clinical Tool}

The candidate clinical tool was shared with clinical pharmacists working on general medical and surgical wards in the study hospital, who piloted it as a part of their routine clinical care for a defined 3-week period in February 2018. As described above, clinical pharmacists working in critical care, the emergency department, and palliative care units of the hospital were excluded from the pilot, and the tool was not applied to any patients who were being followed by the addictions or pain consult services. Pharmacists were asked to use the tool to guide patient assessment 
when any one of the following conditions was met: a combination of opioid and benzodiazepine was ordered, a regularly scheduled opioid medication was ordered, or opioids were ordered for use on an as-needed basis for more than 5 days. These criteria were chosen to maximize pharmacist impact, given that the pilot activities were additional to their existing clinical responsibilities.

\section{Phase 4: Capturing Feedback on the Clinical Tool via Survey}

An online survey was developed by the research team and administered using the Qualtrics Survey tool (first release 2005; Qualtrics, Provo, Utah; https://www.qualtrics.com). The survey included multiple-choice questions relating to the logistics of tool deployment, such as area of care, patient count, and criteria for application of the tool (as described in the previous subsection). It also included Likert-scale questions aimed at assessing pharmacists' perceptions of the tool in terms of facilitating identification of risk factors and interventions, tool usability, and feasibility of incorporating the tool into practice. The questions relating to pharmacists' perceptions of the tool and associated responses are presented in Appendix 2 (available at https://www.cjhponline.ca/index.php/cjhp/issue/view/195/showToc). Respondents were also asked to provide free-text suggestions about how the tool could be improved.

All participants in the pilot trial were invited to participate in the survey; a link to the online survey was sent via e-mail within a 14-day window after completion of the pilot period. No identifying information was gathered in the survey. The survey remained open for a 14-day period, and participants were reminded to complete the survey via an email message sent at the 7-day mark.

\section{RESULTS}

\section{Phase 1: Informing Tool Content and Context}

\section{Literature Search}

The literature search and screening yielded 14 editorials and guidelines, 79 articles pertaining to risk factors or inappropriate prescribing practices, and 3 articles (all from the United States) describing opioid stewardship initiatives. There was significant duplication and overlap in terms of the risk factors identified in the studies; a selection of the most commonly identified risk factors (both non-modifiable and modifiable) and representative studies are summarized in Appendix 3 (available at https://www.cjhp-online.ca/index.php/cjhp/issue/view/195/ show $\mathrm{Toc})$. Examples of non-modifiable risk factors were history of substance use disorder, psychiatric diagnoses, age, absence of prior exposure to opioids, and impaired renal or hepatic function. Modifiable risk factors included excessive opioid dose or frequency, use of parenteral route, prescribing of multiple types of opioids, and use of long-acting opioids for acute pain.
Suboptimal combinations of opioids with benzodiazepines and long-acting/short-acting opioid combinations were also identified as risk factors for opioid-related adverse events. ${ }^{13,14}$ Ultimately, the risk factors chosen for inclusion in the final tool were those frequently cited in the literature and feasible for clinical pharmacists to capture in an inpatient setting. The literature search did not identify any formalized Canadian pharmacy-led approaches to opioid stewardship. Formal programs have been initiated in the United States, but long-term data on patient outcomes have yet to be published.

\section{Focus Groups}

Thirteen clinical pharmacists with work experience ranging from 1 to 30 years participated in a total of 3 focus groups. The key themes arising through analysis with the Theoretical Domains Framework ${ }^{11}$ are presented in Appendix 4 (available at https:// www.cjhp-online.ca/index.php/cjhp/issue/view/195/showToc). Several themes were identified, such as ensuring that pain management is not compromised during opioid stewardship. Focus group participants also expressed a desire to ensure that the program or tool would not overly emphasize avoiding or limiting opioids. Instead, participants felt that it should promote appropriate use of opioids and non-opioid alternatives, with the goal of optimizing pain management. Participants also recognized the significant clinical and environmental context at play when addressing the use of opioid medications. Participants felt that they were sometimes limited by a lack of time and resources to optimize pain control for every patient. Concerns were also raised about barriers pertaining to hospital policy and interprofessional collaboration, with recognition that a pharmacist's clinical area, workload, and local team dynamics could also play a role. It was also recognized that it may be challenging to ensure that medication changes made in hospital are appropriately communicated to community providers. The pharmacists provided a number of practical suggestions about risk factors for inclusion in the tool and strategies to optimize medication use. Additionally, the participants indicated that it might be useful to supplement the tool with educational resources for both patients and interprofessional collaborators.

\section{Phase 2: Formulating the Clinical Tool}

Using the principles outlined in the Methods section and incorporating the results from phase 1 , the research team formulated a preliminary clinical tool. The addictions physician reviewed this preliminary tool, endorsed the content, and suggested minor revisions. The tool was then refined through a series of single-day test cycles involving 4 medical and surgical pharmacists. On the basis of this testing, the tool's formatting was improved, and some of the wording was simplified. The final candidate MORE tool is shown in Appendix 5 (available at https://www.cjhp- 
online.ca/index.php/cjhp/issue/view/195/showToc). The MORE tool focuses on a 4-point process for evaluation of opioid medications: medication and safety review $(\mathrm{M})$; optimization of pain medications $(\mathrm{O})$; reassessment and risk referral $(\mathrm{R})$; and education, planning, and communication (E).

\section{Phases 3 and 4: Piloting the Clinical Tool and Capturing Feedback via Survey}

A total of 14 pharmacists piloted the candidate MORE tool over the course of 3 weeks; the survey was deployed after this pilot period. Nine pharmacists responded to the survey, and these pharmacists had used the tool to assess a total of 33 patients. The 9 respondents indicated that they had reviewed at least 1 to 3 of their patients per week. Five of the 9 respondents thought that the criteria for selecting patients were too limiting, 2 respondents thought the criteria were appropriate, and 2 respondents thought they were too broad.

The survey also asked for respondents' opinions about having the pharmacy computer system generate an automated report to assist them in identifying patients for review. Five of the 9 respondents felt that such a report would be useful, and 6 indicated they would prefer that the program generating the report be run at least once per week.

The questions about pharmacists' perceptions of the tool and the distribution of responses are outlined in Appendix 2. Five of the 9 respondents indicated that the MORE tool had a positive impact on their ability to identify risk factors. The most frequently identified risk factors were lack of adjunct pain medications and non-modifiable risk factors such as advanced age, renal or liver dysfunction, and prior history of opioid use disorder. Five of the 9 respondents described the MORE tool as helpful in identifying possible interventions. The interventions that pharmacists considered most feasible were making recommendations for adjunctive non-opioid pain medications and making recommendations for medications to treat adverse effects of opioids, such as constipation or pruritus.

Eight pharmacists provided responses relating to ease of use of the tool. Four of these respondents felt that the tool was "slightly difficult to use", whereas the other 4 indicated their perception that the tool was easy to use. All 8 respondents indicated that it would be feasible to integrate the tool into their clinical practice. Five of the 8 respondents described the tool as moderately useful $(n=4)$ or very useful $(n=1)$ in improving the management of care for patients receiving opioids, whereas 3 described it as slightly useful.

Participants also provided qualitative responses regarding the feasibility and usability of the tool. Several described the tool as being "too busy" or "too wordy", and one indicated that a "slimmer version would be nice". Another stated that "The biggest challenge is balancing this new initiative with existing work that we need to do." Multiple respondents indicated that the risk factor and intervention checklists were the most useful parts of the tool. One respondent indicated that information regarding "when to refer to different services" was useful. When asked what could be improved, respondents indicated that "the tool could be broken down into more clear steps" and also suggested "having a secondary form to document ongoing monitoring". When prompted for suggestions on additional materials that would help pharmacists to support opioid stewardship, respondents indicated that "counselling sheets for patients on discharge might be helpful", "a laminated card with quick facts" might be beneficial, and "more education and awareness" would be valuable.

\section{DISCUSSION}

Current literature states that the misuse of opioid medications in Canada is leading to significant morbidity and mortality. Collectively, health care professionals (including pharmacists) have acknowledged that misuse of opioids is one of the leading health issues in the country. ${ }^{10}$ To our knowledge, this is the first opioid safety and intervention tool developed for use by hospital pharmacists. Best practices were integrated into the tool to help pharmacists efficiently identify risk factors in their patients and to highlight interventions to avoid opioid-related adverse events. The tool also provides guidance on patient counselling and on ensuring community follow-up for high-risk patients.

Overall, the pharmacists who were involved in the pilot and who responded to the survey felt that the tool helped them to identify risk factors in their patients. They also commented that having a quick reference table helped in the selection of appropriate interventions to optimize therapy and address risk factors. The pharmacists identified several barriers to using the tool, such as time constraints and competing workload in their daily practice. This feedback highlights the potential need for dedicated opioid stewardship resources. Several participants had concerns about the usability of the tool. These concerns seemed to be primarily related to the large amount of information included in the tool. Although it is possible that with repeated use the pharmacists might have become more accustomed to using the tool, the feedback clearly indicates a need to streamline the tool. A logical approach would be to preserve the risk factor assessment and order optimization components of the tool while reducing extraneous information that could be easily located through other reference sources. For example, the detailed information about managing opioid-related adverse effects could be removed from the tool.

We believe that in the context of the current opioid crisis, a streamlined version of the MORE tool could be very useful to hospital pharmacists locally and across Canada. Although the tool was developed at a single centre and was piloted by pharmacists working primarily on general medical and surgical units, the risk factors and interventions included in the tool are broadly applicable. Pharmacists form an integral part of patient-centred health 
This single copy is for your personal, non-commercial use only.

For permission to reprint multiple copies or to order presentation-ready copies for distribution, contact CJHP at publications@cshp.ca

care teams and are well positioned to optimize pain management while ensuring the safe use of opioids when such medications are necessary. As such, the MORE tool could provide a catalyst to promote pharmacists as leaders in opioid stewardship.

This study had a number of potential limitations. Although development of the tool was informed by the literature and input from clinical pharmacists, there was some subjectivity in prioritizing the risk factors and interventions and in the overall design of the tool. This study assessed clinical pharmacists' perceptions of the MORE tool but was not designed to assess clinical outcomes such as quality of pain management or frequency of opioid-related adverse events. Five of the 14 pharmacists who piloted the tool did not complete the survey. The reasons are unclear, but may be related to competing responsibilities or their work schedules. Finally, the tool is not intended for patients with cancer-related or end-of-life pain or for patients in critical care or the emergency department and was not evaluated in these settings.

\section{CONCLUSION}

Our research team developed an opioid safety and intervention tool that was well received in a pilot study of clinical pharmacists. The tool was particularly helpful in identifying risk factors and possible interventions for patients with non-malignant pain admitted to general medical and surgical units. The results indicate that streamlining the information and design would improve the overall usability of the tool and its acceptance by clinical pharmacists.

\section{References}

1. Report: Together, we can do this: Strategies to address British Columbia's prescription opioid crisis. Recommendations from the British Columbia node of the Canadian Research Initiative on Substance Misuse. Vancouver (BC): BC Centre for Excellence in HIV/AIDS; 2015 Nov.

2. Special Advisory Committee on the Epidemic of Opioid Overdoses. National report: Apparent opioid-related harms in Canada web based report. Ottawa (ON): Public Health Agency of Canada; 2019 Dec [cited 2020 Jan 13]. Available from: https://health-infobase.canada.ca/datalab/nationalsurveillance-opioid-mortality.html

3. Illicit drug overdose deaths in BC January 1, 2007-May 31, 2017. Burnaby (BC): BC Coroners Service; 2017.

4. Ghafoor VL, Phelps P, Pastor J. Implementation of a pain management stewardship program. Am J Health Syst Pharm. 2013;70(23):2070-5.

5. Mars SG, Bourgois P, Karandinos G, Montero F, Ciccarone D. "Every 'never' I ever said came true": transitions from opioid pills to heroin injecting. Int J Drug Policy. 2014;25(2):257-66.

6. Narcotic drugs: estimated world requirements for 2012, statistics for 2010. Vienna (AT): International Narcotics Control Board; 2011.

7. Fischer B, Argento E. Prescription opioid related misuse, harms, diversion and interventions in Canada: a review. Pain Physician. 2012;15(3 Suppl): ES191-203.
8. Calcaterra SL, Yamashita TE, Min SJ, Keniston A, Frank JW, Binswanger IA. Opioid prescribing at hospital discharge contributes to chronic opioid use. J Gen Intern Med. 2016;31(5):478-85.

9. Freedman S, Izzo S, Keenan C, Musco S, Daugherty A, Ostrander S. Reducing opioid misuse and abuse. Advisory Board; 2017 Jun 13 [cited 2017 Oct 16]. Available from: https://www.advisory.com/research/pharmacyexecutive-forum/research-reports/2017/reducing-opioid-misuse-abuse. Login required to access content.

10. Controlled drugs and substances in hospitals and healthcare facilities: guidelines on secure management and diversion prevention. Ottawa (ON): Canadian Society of Hospital Pharmacists; 2019 Feb [cited 2019 Jun 11]. Available from: https://www.cshp.ca/sites/default/files/files/publications/Official\%20 Publications/Guidelines/Controlled\%20Drugs\%20and\%20Substances\%20 in $\% 20$ Hospitals $\% 20$ and $\% 20$ Healthcare\%20Facilities_2019_02-28.pdf

11. Cane J, O'Connor D, Michie S. Validation of the theoretical domains framework for use in behaviour change and implementation research. Implement Sci. 2012;7:Article 37.

12. Michie S, Johnston M, Abraham C, Lawton R, Parker D, Walker A, et al. Making psychological theory useful for implementing evidence based practice: a consensus approach. Qual Saf Health Care. 2005;14(1):26-33.

13. Nosyk B, Fischer B, Sun H, Marsh DC, Kerr T, Rehm JT, et al. High levels of opioid analgesic co-prescription among methadone maintenance treatment clients in British Columbia, Canada: results from a population-level retrospective cohort study. Am J Addict. 2014;23(3):257-64

14. Cunningham CM, Hanley GE, Morgan S. Patterns in the use of benzodiazepines in British Columbia: examining the impact of increasing research and guideline cautions against long-term use. Health Policy. 2010;97 $(2-3): 122-9$

Brendan Woods, BSCPharm, ACPR, is a Clinical Pharmacist with Royal University Hospital, Saskatchewan Health Authority, Saskatoon, Saskatchewan

Michael Legal, BSCPharm, PharmD, ACPR, FCSHP, is Clinical Pharmacy Manager with Lower Mainland Pharmacy Services, Vancouver, British Columbia.

Stephen Shalansky, BSCPharm, PharmD, ACPR, FCSHP, is a Pharmacy Clinical Coordinator with Providence Health Care, Lower Mainland Pharmacy Services, Vancouver, British Columbia.

Tamara Mihic, BScPharm, PharmD, ACPR, is a Clinical Pharmacy Specialist with Providence Health Care, Lower Mainland Pharmacy Services Vancouver, British Columbia.

Winnie Ma, BSCPharm, ACPR, is a Pharmacy Clinical Supervisor with Providence Health Care, Lower Mainland Pharmacy Services, Vancouver, British Columbia.

Competing interests: None declared.

Disclaimer: Stephen Shalansky is the Editor of the Canadian Journal of Hospital Pharmacy. He was not involved in the editorial decision-making process for this article.

\section{Address correspondence to:}

Dr Michael Legal

St Paul's Hospital

1081 Burrard Street

Vancouver BC V6Z 1Y6

e-mail: mlegal@providencehealth.bc.ca

Funding: None received. 